\title{
Number of Participants
}

\section{Number of Presentations}

\begin{tabular}{l|r}
\hline Panel Discussions & 2 \\
\hline Plenary Lectures & 12 \\
\hline Meet-the-Professor & 64 \\
\hline Symposia & 415 \\
\hline JES-Sponsored Symposia & 49 \\
\hline Oral Hot Topics & 35 \\
\hline Oral Sessions & 80 \\
\hline Poster Presentations & 1,188 \\
\hline Luncheon Seminars & 16 \\
\hline Satellite Symposia & 3 \\
\hline Total & 1,864 \\
\hline
\end{tabular}

Official Satellite Symposia

13

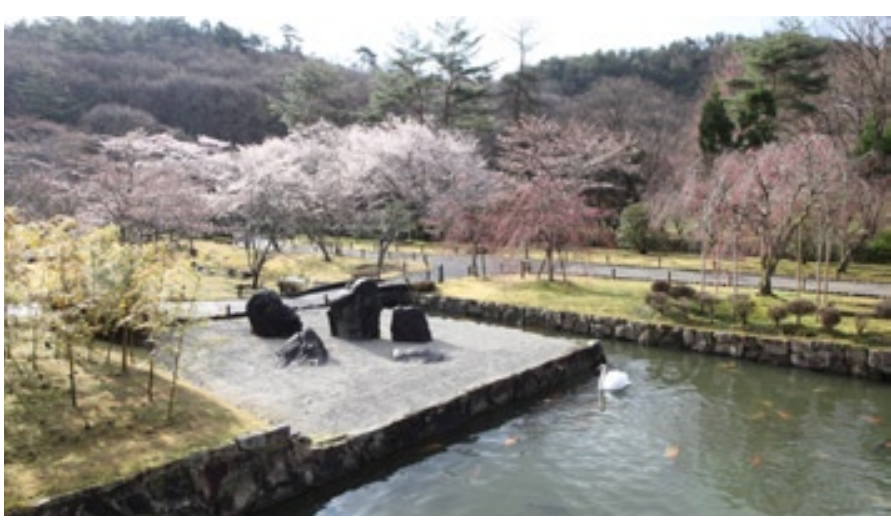

Number of Registrants in Each Category

\begin{tabular}{l|r|r|r}
\hline & Japan & Overseas & \multicolumn{1}{|c}{ Total } \\
\hline Invitee & 102 & 258 & 360 \\
\hline Regular & 1,978 & 1,470 & 3,448 \\
\hline Student/Fellow & 297 & 144 & 441 \\
\hline Accompany & 29 & 230 & 259 \\
\hline \multicolumn{1}{c|}{ Total } & 2,406 & 2,102 & 4,508 \\
\hline
\end{tabular}

\section{Nationalities of the Registrants}

\begin{tabular}{|c|c|c|c|}
\hline Country & Regular & $\begin{array}{l}\text { Student/ } \\
\text { Fellow }\end{array}$ & Total \\
\hline Total & 3,448 & 441 & 3,889 \\
\hline Japan & 1,978 & 297 & 2,275 \\
\hline Overseas Total & 1,470 & 144 & 1,614 \\
\hline Albania & 3 & 0 & 3 \\
\hline Argentina & 3 & 0 & 3 \\
\hline Australia & 43 & 9 & 52 \\
\hline Austria & 1 & 0 & 1 \\
\hline Bangladesh & 2 & 1 & 3 \\
\hline Belarus & 1 & 1 & 2 \\
\hline Belgium & 8 & 1 & 9 \\
\hline Brazil & 20 & 1 & 21 \\
\hline Bulgaria & 18 & 0 & 18 \\
\hline Canada & 6 & 3 & 9 \\
\hline China & 257 & 10 & 267 \\
\hline Colombia & 2 & 0 & 2 \\
\hline Czech Republic & 16 & 2 & 18 \\
\hline Denmark & 9 & 0 & 9 \\
\hline Egypt & 4 & 0 & 4 \\
\hline Estonia & 8 & 0 & 8 \\
\hline Finland & 1 & 3 & 4 \\
\hline France & 10 & 0 & 10 \\
\hline Georgia & 10 & 0 & 10 \\
\hline Germany & 16 & 0 & 16 \\
\hline
\end{tabular}

\begin{tabular}{l|r|r|r}
\hline Country & Regular & $\begin{array}{l}\text { Student/ } \\
\text { Fellow }\end{array}$ & \multicolumn{1}{l}{ Total } \\
\hline Ghana & 1 & 0 & 1 \\
\hline Greece & 12 & 0 & 12 \\
\hline Hong Kong & 3 & 0 & 3 \\
\hline Hungary & 24 & 0 & 24 \\
\hline India & 113 & 5 & 118 \\
\hline Indonesia & 24 & 3 & 27 \\
\hline Iran & 2 & 2 & 4 \\
\hline Israel & 11 & 0 & 11 \\
\hline Italy & 17 & 3 & 20 \\
\hline Kuwait & 5 & 1 & 6 \\
\hline Latvia & 14 & 1 & 15 \\
\hline Lithuania & 45 & 0 & 45 \\
\hline Malaysia & 17 & 0 & 17 \\
\hline Mauritius & 1 & 0 & 1 \\
\hline Mexico & 2 & 0 & 2 \\
\hline Netherlands & 2 & 1 & 3 \\
\hline New Zealand & 4 & 1 & 5 \\
\hline Nigeria & 3 & 1 & 4 \\
\hline Norway & 2 & 1 & 3 \\
\hline Oman & 1 & 0 & 1 \\
\hline Peru & 1 & 0 & 1 \\
\hline Philippines & 15 & 4 & 19 \\
\hline Poland & 62 & 2 & 64 \\
\hline & & & \\
\hline
\end{tabular}

\begin{tabular}{l|r|r|r}
\hline Country & Regular & \multicolumn{1}{l}{$\begin{array}{l}\text { Student } \\
\text { Fellow }\end{array}$} & \multicolumn{1}{l}{ Total } \\
\hline Portugal & 13 & 3 & 16 \\
\hline Qatar & 1 & 0 & 1 \\
\hline Republic of Korea & 21 & 37 & 58 \\
\hline Romania & 28 & 0 & 28 \\
\hline Russia & 38 & 2 & 40 \\
\hline Saudi Arabia & 11 & 0 & 11 \\
\hline Serbia & 13 & 1 & 14 \\
\hline Singapore & 13 & 1 & 14 \\
\hline Slovak Republic & 19 & 1 & 20 \\
\hline Slovenia & 2 & 0 & 2 \\
\hline South Africa & 2 & 1 & 3 \\
\hline Spain & 66 & 1 & 67 \\
\hline Sweden & 15 & 9 & 24 \\
\hline Switzerland & 4 & 0 & 4 \\
\hline Taiwan & 61 & 14 & 75 \\
\hline Thailand & 176 & 1 & 177 \\
\hline Turkey & 57 & 1 & 58 \\
\hline Ukraine & 6 & 0 & 6 \\
\hline United Arab Emirates & 1 & 0 & 1 \\
\hline United Kingdom & 28 & 4 & 32 \\
\hline United States & 59 & 11 & 70 \\
\hline Viet Nam & 16 & 1 & 17 \\
\hline Zimbabwe & 1 & 0 & 1 \\
\hline & & & \\
\hline
\end{tabular}

